\title{
Applied value of 3D printing technique in surgical treatment of acetabular fractures
}

\section{Guofeng Xia}

Orthopedics Ward One, No. 971 Army Navy hospital of People's Liberation, Qingdao Shandong

Qi Liu

Orthopedics Ward One, No. 971 Army Navy hospital of People's Liberation, Qingdao Shandong

Peifeng Sun ( $\square$ sopy104@163.com )

Orthopedics Ward One, No. 971 Army Navy hospital of People's Liberation, Qingdao Shandong

\section{Research Article}

Keywords: Acetabular fractures, 3D printing technology, Assisted surgery, Application value

Posted Date: March 7th, 2022

DOI: https://doi.org/10.21203/rs.3.rs-1353312/v1

License: (a) This work is licensed under a Creative Commons Attribution 4.0 International License. Read Full License 


\section{Abstract}

\section{Purposes $\llbracket$}

To explore the effect of 3D printing technique for the surgical treatment of acetabular fractures and provide reference for improving clinical curative effect.

\section{Methods 【}

94 acetabular fracture patients from 2006 to 2016 were cl assified into conditional group, according to the Judet-Letournel classification were divided into simple fracture group 43 cases and complex fracture group 51 cases. 46 acetabular fracture patients were classified into 3D group since 2017, according to Letournel classification were divided into 25 cases of simple fracture group and complex fracture group of 21 cases. Operation time, intraoperative blood loss, perioperative blood transfusion, time of intraoperative fluoroscopy and postoperative drainage, surgical imaging results analysis, postoperative functional recovery of hip, postoperative complications were compared between traditional and 3D group respectively in simple and complicated fracture.

\section{Results}

In simple fracture, there were no significantly difference in the operation time, intraoperative blood loss, perioperative blood transfusion, time of intraoperative fluoroscopy and postoperative drainage, surgical imaging results analysis, postoperative functional recovery of hip, postoperative complications between traditional and 3D group $(P>0.05)$

In complicated fracture, there were significantly difference in operation time, intraoperative blood loss, perioperative blood transfusion, times of intraoperative fluoroscopy, surgical imaging results, functional recovery of the hip, incidence of incision infection between conditional and 3D group $(P<0.05)$. There were no significantly difference in postoperative drainage, the incidences of postoperative iatrogenic neurological symptoms, traumatic arthritis and heterotopic ossification between conditional and 3D group. $(\mathrm{P}<0.05)$

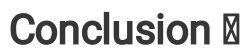

The 3D printing technique of assisted surgical treatment of simple acetabular fractures had no significant effect on operation time, intraoperative blood loss, perioperative blood transfusion, intraoperative perspective and postoperative drainage; and 3D printing technology for patients with complicated acetabular fractures auxiliary Surgical treatment can significantly shorten the operation time, reduce intraoperative blood loss and perioperative blood transfusion, and reduce the number of intraoperative fluoroscopy; 3D printing technology can reduce the risk of postoperative wound infection, regardless of the use of complicated surgical treatment of acetabular fractures.

\section{Introduction}


Acetabular fracture is the type of fracture involving high energy damage to the hip, with deep anatomical position and complex anatomical relationship ${ }^{[1]}$. The damage may be accompanied by other site damage, so it is relatively difficult to treat ${ }^{[2]}$. In the past decade, 3D technology has increasingly been used in acetabular fracture treatment. 3D printing is useful for classifying acetabular fractures and for teaching purposes ${ }^{[3-6]}$. For instance, 3D printed models may improve the quality of surgical trainees' preoperative understanding of the spatial complexity of fractures ${ }^{[7]}$ In addition, a randomised controlled trial showed that using a 3D interactive software system for teaching acetabular fracture classification improved the classification accuracy ${ }^{[8]}$. Moreover, the use of 3D printed fracture models has improved fracture classification in comparison with 2D/3D CT images, due to enhanced tactile feedback of the complex geometry. ${ }^{[4-5]}$ This may result in a shorter time needed to classify the acetabular fractures and a higher interobserver agreement as compared to the evaluation of these fractures using $2 \mathrm{D}$ CT images ${ }^{[3]}$

For patients with acetabular fracture, special shaped titanium plate combined with square area screw system and reconstruction of internal fixation system of bone connecting plate have been carried out at home and abroad, which is not only simple to operate, but also has good stability ${ }^{[9]}$.

The vast majority of scholars ${ }^{[10-11]}$ confirming that 3D printing technology-assisted surgical treatment not only realizes the reproduction of the fracture site, prompts the fracture classification to be clear before surgery, selects the appropriate fixation method and material in advance, and is pre-shaped, which can be directly used during surgery, but also requires only fine adjustment for some mismatches, which realizes the surgical accuracy and saves the operation time to a great extent. The study on the difference in the effect of 3D printing technique-assisted surgery for simple acetabular fracture and complex acetabular fracture is rare. This study specially compared the differences in the operation time, intraoperative blood loss, postoperative drainage volume, incision infection rate, surgical reduction effect and postoperative hip joint function recovery effect were different between the traditional surgical group and the 3D printing technology-assisted surgery group in the simple fracture group, observe whether there is loss of postoperative reduction in the two groups; also observe the difference in the above indicators between the traditional surgery group and 3D printing technology assisted surgery group among the patients in the complex fracture group, in order to explore which 3D printing technology has the greatest application value in the simple and complex types of acetabular fractures.

\section{Materials And Methods}

\section{Research data}

\subsection{General Information}

The medical records of 94 patients with acetabular fractures caused by trauma who were admitted to our department during the 10-year period from December 2006 to December 2016 and met the indications for traditional surgery were retrospectively analyzed and included in the traditional surgery group, and they were divided into simple fracture group $(n=43)$ and complex fracture group $(n=51)$ according to the 
Judet-Letournel classification of acetabular fractures. Among them, there were 24 male patients and 19 female patients in the simple fracture group, aged 32 to 67 years, with an average age of $(49.23 \pm 11.05)$ years. The time from fracture to admission for surgery ranged from 1 day to 3 weeks, with an average of $(1.02 \pm 0.28)$ weeks. Among them, 23 patients were injured due to traffic accidents, 14 caused by highaltitude fall, and 6 patients were injured due to violence; there were 30 male patients and 21 female patients in the complex fracture group, aged 31 to 65 years, with an average age of $(48.61 \pm 10.96)$ years. The time from fracture to admission for surgery ranged from 3 days to 3 weeks, with an average of (1.12 \pm 0.41 ) weeks. Among them, 27 patients were injured due to traffic accidents, 16 caused by high-altitude fall, and 8 patients were injured due to violence.

A total of 46 patients with acetabular fracture who met the surgical indications since 2017 were enrolled. All patients were treated with 3D printing technique-assisted surgery. They were included in the 3D printing technique-assisted surgery group and divided into simple fracture group $(n=25)$ and complex fracture group ( $n=21)$ according to Judet-Letournel classification of acetabular fracture. Among them, there were 13 male patients and 12 female patients in the simple fracture group, aged 33 to 66 years, with an average age of $(49.12 \pm 10.03)$ years. The time from fracture to admission for surgery ranged from 5 days to 3 weeks, with an average of $(1.08 \pm 0.38)$ weeks. The causes of injury were traffic accidents in 16 patients, caused by high-altitude fall in 6 patients, and violent impact injury in 3 patients. In the complex fracture group, there were 12 male patients and 9 female patients, aged 31 to 68 years, with an average age of $(48.69 \pm 10.79)$ years. The time from fracture to admission for surgery ranged from 2 days to 2.5 weeks, with an average of $(1.12 \pm 0.35)$ weeks. The causes of injury were traffic accidents in 13 patients, caused by high-altitude fall in 5 patients, and violent impact injury in 3 patients

In the simple fracture group, there was no significant difference in gender, age, cause of injury, course of disease and other baseline data between the traditional surgery group and 3D printing technique-assisted surgery group $(P>0.05)$, demonstrating that the two groups of patients could be compared and analyzed; and in the complex fracture group, there was no significant difference in the above general data between the traditional surgery group and 3D printing technique-assisted surgery group $(P>0.05)$. A comparative study could be performed between the two groups.

\subsection{Inclusion criteria}

The patients were over 18 years old; all patients were classified according to Letournel-Judet classification criteria; The time from fracture to admission for surgery was less than 3 weeks; the patients volunteered to participate in this study, their families gave informed consent, and signed a surgery-related agreement; the study was approved by the medical ethics committee of the hospital.

\section{Patients who do not meet the inclusion criteria; Patients with severe bone defects; Patients with severe osteoporosis; Patients with severe}




\section{mental illness and paraplegia; Patients with incomplete case data; Patients with loss of follow-up; Patients who voluntarily withdraw from the study or transfer halfway.}

\section{Methods}

Preoperative treatment of patients in the two groups: patients with posterior dislocation of the hip underwent manual reduction immediately after admission. After admission, all patients underwent 6 to 8 $\mathrm{kg}$ traction of the supracondylar bone, and all patients underwent routine preoperative $\mathrm{X}$-ray examination and thin-section scanning using 64-slice spiral CT (produced by Philips, the Netherlands) to observe the pelvis and upper femur, with a pitch set at $0.5 \mathrm{~mm}$, a current set at $100 \mathrm{mAs}$, and a voltage set at $100 \mathrm{kV}$ during scanning. Prepare $400 \sim 800 \mathrm{ml}$ of allogeneic blood in advance, and prepare the autologous blood transfusion set. Give antibiotic injection $0.5 \sim 2.0$ hours before operation to prevent infection. Perform general anesthesia through endotracheal intubation before operation, and the operation is completed by the same group of surgeons

3D print-assisted surgery group: the 64-slice spiral CT scan results were imported into the 3D image editing processing software Mimics 14.0 in DICOM format, three-dimensional reconstruction was performed at the fracture site, Figure 1, the relative space of the fracture was accurately observed, and virtual surgical reduction was performed, the appropriate surgical approach was selected using the fracture reduction model, and the position of the preset plate and the exact site of the screw hole were determined by drawing a line on the model. Create a cylindrical virtual screw path simulation with the diameter of $2.5 \mathrm{~mm}$, adjust the direction and length of each virtual screw according to the actual situation in the surgical operation, and measure the screw length. Arrange a red curve on the model through the Create Spline function to mark the optimal position of implanted plate, then perform three-dimensional cutting for the fracture model at the preset plate position. The size is according to the actual reconstructed plate size. Import the format into the 3D printing software as STL format, and then print the physical module with the 3D printing model. Figure 2. Select the reconstruction plate in combination with the 3D printed model, and select the appropriate number of holes. Bend the plate in a large arc at one time as far as possible to avoid repeated bending. The procedure was reduced according to a preset protocol and compared with a pre-bent reconstruction plate to ensure perfect fit between the reconstruction plate and the bone surface.

A 3D printed model after reset; B Preset plate, virtual implant screw on model

After the operation, the drainage tube was routinely placed for 48 hours to 72 hours, and the patient's lower limb sensation, movement and blood supply were examined after recovery from anesthesia. Postoperative routine X-ray and CT reexamination were performed to observe the fracture healing, and routine rehabilitation exercises were performed according to the patient's recovery to promote the recovery of hip joint function. Figures 3 to 10 for preoperative and postoperative imaging data of patients, 1:1 physical model of 3D printing, virtual surgical reduction, design of pre-bent plate, and design of screw position. 


\section{Observational indicators}

The differences in the operation time, intraoperative blood loss, postoperative drainage volume, perioperative blood transfusion volume, intraoperative fluoroscopy times, incision infection rate, surgical reduction effect and postoperative hip joint function recovery effect between the traditional surgery group and 3D printing technique-assisted surgery group in the simple surgery group were compared and analyzed. Postoperative reduction was observed in the two groups; postoperative complications were statistically analyzed: wound healing, loss of reduction, traumatic arthritis and iatrogenic neurological symptoms and incision infection rate were mainly observed. The differences in the above indicators between the traditional surgical group and 3D printing technique-assisted surgery group in the complex fracture group were also observed. To further investigate which 3D printing technology has the greatest application value in the simple and complex types of acetabular fractures.

Imaging evaluation: Meta score was used to evaluate the reduction of acetabular fracture after operation. Criteria: excellent: the fracture was not displaced after operation; good: the postoperative fracture displacement distance was within $1 \mathrm{~mm}$; fair: the postoperative fracture displacement distance was within $1 \sim 3 \mathrm{~mm}$; poor: the postoperative fracture displacement distance was more than $3 \mathrm{~mm}$. Overall response rate $=($ excellent cases + good cases + fair cases $) /$ total cases $\times 100 \%{ }^{[12]}$.

Hip function evaluation: The postoperative hip function was evaluated by the patient's pain, walking and range of joint motion according to the modified MerleD 'Aubigne and Postel scoring criteria, In this criteria, the pain score ranges from 2 to 6 , which are severe pain and limits walking; moderate to severe pain, which allows walking; pain after walking, which is relieved after rest; mild pain or intermittent pain; and no pain. Walking score from 12 to 6 , respectively: unable to walk; very limited; limited use of walking aids; requires cane or crutch for long distance walking; slight limp, requires no cane; normal. The range of motion score is calculated as the percentage of postoperative range of motion to the normal range of motion, 1 point is < $50 \%, 2$ points are $50 \% \sim 60 \%, 3$ points are $60 \% \sim 70 \%, 4$ points are $70 \% \sim 80 \%, 5$ points are $80 \% \sim 95 \%, 6$ points are $95 \% \sim 100 \%$. The total score is obtained by summing the three parts. A total score of 18 points is considered excellent, a score of $15 \sim 17$ points is considered good recovery, if a score of $13 \sim 14$ points is fair, and a score of less than 13 points indicates that the patient's postoperative hip function recovery effect is poor. Excellent rate of hip joint function recovery $=$ (excellent cases + good cases $) /$ total cases $x$ $100 \%$ [13]

\section{Statistical methods}

Data were processed using SPSS 19.0 statistical software. Measurement data were first tested for normality, and those who met the normal distribution were subjected to two independent sample t-tests, which were expressed as ( $x \pm s$ ), and paired t-tests were used for comparison before and after surgery in groups; Enumeration data were described by $n(\%), \chi 2$ test was used, chi-square correction method was used for cells with minimum theoretical frequency $<5$, and Fisher's exact test was used for cells with minimum theoretical frequency $<1$, and $\mathrm{P}<0.05$ indicated that the difference was statistically significant. 


\section{Results}

\section{Statistical analysis of intraoperative and postoperative basic situation of two different surgical methods in simple fracture group}

As shown in Table 1, in patients with simple fracture, the operation time, intraoperative blood loss, perioperative blood transfusion volume, intraoperative fluoroscopy times and postoperative drainage volume in the traditional surgery group and 3D printing technique-assisted surgery group showed no statistical difference $(P>0.05)$.

\section{Statistical analysis of intraoperative and postoperative basic situation of two different surgical methods in complex fracture group}

As shown in Table 2, in patients with complex fractures, the operation time, intraoperative blood loss, perioperative blood transfusion and intraoperative fluoroscopy times in 3D printing technique-assisted surgery group were significantly shorter than those in traditional surgery group, and the differences had statistical significance $(P<0.05)$. The difference in postoperative drainage volume had no statistical significance $(P>0.05)$.

\section{Analysis of imaging results of two different surgical methods in patients with simple fracture}

As shown in Table 3, in patients with simple fracture, there was no significant difference in the imaging efficacy results 3 months after operation in the 3D printing technique-assisted surgery group $(P>0.05)$, in which the effective rate of traditional surgery was $95.35 \%$, and the effective rate of 3D printing techniqueassisted surgery was $92.00 \%$, and the difference had no statistical significance $(X 2=0.001, P=0.975)$.

\section{Analysis of imaging results of two different surgical methods in patients with complex fractures}

As shown in Table 4, in patients with complex fractures, there was significant difference in the 3-month postoperative follow-up imaging efficacy results between the two different surgical methods $(P<0.05)$, and the overall response rate was $95.24 \%$ in the 3D printing technique-assisted surgery group, higher than $70.59 \%$ in the traditional surgery group, and the difference had statistical significance $(\chi 2=3.900, P=$ $0.048)$.

\section{Comparison of the effect of two different surgical methods on hip joint function recovery in patients with simple fracture}


As shown in Table 5, in patients with simple fracture, there was no significant difference in the efficacy of hip joint function recovery during follow-up at 3 months after operation between the 3D printing techniqueassisted surgery group and the traditional surgery group $(P>0.05)$. The excellent and good rate of hip joint function recovery was $86.05 \%$ in the traditional surgery group and $80.00 \%$ in the $3 \mathrm{D}$ printing techniqueassisted surgery group, and the difference had no statistical significance $(\chi 2=0.097, P=0.756)$.

\section{Comparison of the effect of two different surgical methods on hip joint function recovery in patients with complex fractures}

As shown in Table 6, among patients with complex fractures, there was statistical difference in the effect of hip joint function recovery during follow-up at 3 months after operation in the traditional surgery group $(P<0.05)$, and the excellent and good rate of hip joint function recovery in the 3D printing techniqueassisted surgery group was $66.67 \%$, significantly higher than $43.14 \%$ in the traditional surgery group, and there was statistical significance $(X 2=3.294, P=0.070)$

\section{Analysis of postoperative complications in patients with simple fracture treated with different surgical methods}

As shown in Table 7, in patients with simple fracture, the incidence rate of complications such as postoperative iatrogenic neurological symptoms, traumatic arthritis and heterotopic ossification in 3D printing technology-assisted surgery group was not statistically different from that in traditional surgery group $(P>0.05)$.

\section{Analysis of postoperative complications in patients with complex fractures treated with different surgical methods}

As shown in Table 7, in patients with complex fractures, the incidence rate of complications such as postoperative iatrogenic neurological symptoms, traumatic arthritis and heterotopic ossification in 3D printing technique-assisted surgery group was not statistically different from that in traditional surgery group $(P>0.05)$, and the incidence rate of postoperative incision infection in 3D printing techniqueassisted surgery group was significantly lower than that in traditional surgery group, and the difference had statistical significance $(P<0.05)$.

Table 1 Statistical analysis of intraoperative and postoperative basic situation of two different surgical methods in simple fracture group 


\begin{tabular}{|llllll|}
\hline Group & $\begin{array}{l}\text { Operation } \\
\text { time }(\mathrm{min})\end{array}$ & $\begin{array}{l}\text { Intraoperative } \\
\text { blood loss }(\mathrm{ml})\end{array}$ & $\begin{array}{l}\text { Perioperative } \\
\text { blood } \\
\text { transfusion } \\
(\mathrm{ml})\end{array}$ & $\begin{array}{l}\text { Intraoperative } \\
\text { fluoroscopy } \\
\text { times }\end{array}$ & $\begin{array}{l}\text { Postoperative } \\
\text { drainage } \\
\text { volume }\end{array}$ \\
\hline $\begin{array}{l}\text { Traditional } \\
\text { surgery } \\
\text { group }\end{array}$ & $188.14 \pm 29.80$ & $1101.28 \pm 318.21$ & $763.79 \pm 298.04$ & $8.88 \pm 1.91$ & $371.02 \pm 44.69$ \\
\hline $\begin{array}{l}\text { 3D Printing } \\
\begin{array}{l}\text { Technology } \\
\text { Assisted }\end{array}\end{array}$ & $185.20 \pm 24.94$ & $972.80 \pm 288.59$ & $616.40 \pm 297.69$ & $8.40 \pm 1.12$ & $366.20 \pm 57.19$ \\
$\begin{array}{l}\text { Surgery } \\
\text { Group }\end{array}$ & & & & & \\
\hline $\mathrm{t}$ & 0.415 & 1.737 & 1.967 & 1.157 & 0.387 \\
\hline $\mathrm{P}$ & 0.679 & 0.087 & 0.053 & 0.251 & 0.700 \\
\hline
\end{tabular}

Table 2 Statistical analysis of intraoperative and postoperative basic situation of two different surgical methods in complex fracture group

\begin{tabular}{|llllll|}
\hline group & $\begin{array}{l}\text { Operation } \\
\text { time }(\mathrm{min})\end{array}$ & $\begin{array}{l}\text { Intraoperative } \\
\text { blood loss }(\mathrm{ml})\end{array}$ & $\begin{array}{l}\text { Perioperative } \\
\text { blood } \\
\text { transfusion }(\mathrm{ml})\end{array}$ & $\begin{array}{l}\text { Intraoperative } \\
\text { fluoroscopy } \\
\text { times }\end{array}$ & $\begin{array}{l}\text { Postoperative } \\
\text { drainage } \\
\text { volume }\end{array}$ \\
\hline $\begin{array}{l}\text { Traditional } \\
\text { surgery } \\
\text { group }\end{array}$ & $230.14 \pm 37.59$ & $1535.49 \pm 362.91$ & $1176.47 \pm 340.93$ & $11.01 \pm 1.50$ & $408.73 \pm 92.61$ \\
\hline $\begin{array}{l}\text { 3D Printing } \\
\text { Technology } \\
\text { Assisted }\end{array}$ & $167.62 \pm 21.43$ & $1047.14 \pm 224.06$ & $639.52 \pm 281.96$ & $8.29 \pm 1.27$ & $373.81 \pm 59.01$ \\
$\begin{array}{l}\text { Surgery } \\
\text { Group }\end{array}$ & & & & & \\
\hline $\mathrm{t}$ & 7.141 & 5.720 & 6.369 & 7.319 & 0.097 \\
\hline $\mathrm{P}$ & $<0.01$ & $<0.01$ & $<0.01$ & $<0.01$ & 0.115 \\
\hline
\end{tabular}

Table 3 Analysis of imaging results of two different surgical methods in patients with simple fracture

\begin{tabular}{|llllllll|}
\hline Group & $\begin{array}{l}\text { Example } \\
\text { number }\end{array}$ & Superior & Good & General & Poor & Z & P \\
\hline Traditional surgery group & 43 & 24 & 13 & 4 & 2 & -0.179 & 0.858 \\
\hline $\begin{array}{l}\text { 3D Printing Technology } \\
\text { Assisted Surgery Group }\end{array}$ & 25 & 15 & 6 & 2 & 2 & & \\
\hline
\end{tabular}

Table 4 Analysis of imaging results of two different surgical methods in patients with complex fractures 


\begin{tabular}{|c|c|c|c|c|c|c|c|}
\hline Group & $\begin{array}{l}\text { Example } \\
\text { number }\end{array}$ & Superior & Good & General & Poor & Z & $\mathrm{P}$ \\
\hline Traditional surgery group & 51 & 10 & 14 & 12 & 15 & \multirow[t]{2}{*}{-3.310} & \multirow[t]{2}{*}{0.001} \\
\hline $\begin{array}{l}\text { 3D Printing Technology } \\
\text { Assisted Surgery Group }\end{array}$ & 21 & 11 & 7 & 2 & 1 & & \\
\hline
\end{tabular}

Table 5 Comparison of the effect of two different surgical methods on hip joint function recovery in patients with simple fracture

\begin{tabular}{|c|c|c|c|c|c|c|c|}
\hline Group & $\begin{array}{l}\text { Example } \\
\text { number }\end{array}$ & Superior & Good & General & Poor & Z & $P$ \\
\hline Traditional surgery group & 43 & 22 & 15 & 2 & 4 & \multirow[t]{2}{*}{-0.369} & \multirow[t]{2}{*}{0.712} \\
\hline $\begin{array}{l}\text { 3D Printing Technology } \\
\text { Assisted Surgery Group }\end{array}$ & 25 & 12 & 8 & 3 & 2 & & \\
\hline
\end{tabular}

Table 6 Comparison of the effect of two different surgical methods on hip joint function recovery in patients with complex fractures

\begin{tabular}{|c|c|c|c|c|c|c|c|}
\hline Group & $\begin{array}{l}\text { Example } \\
\text { number }\end{array}$ & Superior & Good & General & Poor & Z & $P$ \\
\hline Traditional surgery group & 51 & 13 & 9 & 10 & 19 & \multirow[t]{2}{*}{-2.059} & \multirow[t]{2}{*}{$0.03 c$} \\
\hline $\begin{array}{l}\text { 3D Printing Technology } \\
\text { Assisted Surgery Group }\end{array}$ & 21 & 8 & 6 & 5 & 2 & & \\
\hline
\end{tabular}

Table 7 Analysis of postoperative complications in patients with simple fracture treated with different surgical methods fractures

\begin{tabular}{|lllllc|}
\hline Group & $\begin{array}{l}\text { Example } \\
\text { number }\end{array}$ & $\begin{array}{l}\text { latrogenic } \\
\text { neurological } \\
\text { symptoms }\end{array}$ & $\begin{array}{l}\text { Traumatic } \\
\text { arthritis }\end{array}$ & $\begin{array}{l}\text { Heterotopic } \\
\text { ossification }\end{array}$ & $\begin{array}{l}\text { Wound } \\
\text { infection }\end{array}$ \\
\hline Traditional surgery group & 43 & 4 & 1 & 1 & 4 \\
\hline $\begin{array}{l}\text { 3D Printing Technology } \\
\text { Assisted Surgery Group }\end{array}$ & 25 & 1 & 0 & 1 & 1 \\
\hline$X^{2}$ & & 0.106 & $/$ & $/$ & 0.106 \\
\hline$P$ & & 0.744 & 1.000 & $1.000^{*}$ & 0.744 \\
\hline
\end{tabular}

\section{Note: * indicates analysis by Fisher's exact test}

Table 8 Analysis of postoperative complications in patients with complex fractures treated with different surgical methods 


\begin{tabular}{|lllllc|}
\hline Group & $\begin{array}{l}\text { Example } \\
\text { number }\end{array}$ & $\begin{array}{l}\text { latrogenic } \\
\text { neurological } \\
\text { symptoms }\end{array}$ & $\begin{array}{l}\text { Traumatic } \\
\text { arthritis }\end{array}$ & $\begin{array}{l}\text { Heterotopic } \\
\text { ossification }\end{array}$ & $\begin{array}{l}\text { Wound } \\
\text { infection }\end{array}$ \\
\hline Traditional surgery group & 51 & 6 & 2 & 2 & 12 \\
\hline $\begin{array}{l}\text { 3D Printing Technology } \\
\text { Assisted Surgery Group }\end{array}$ & 21 & 1 & 0 & 0 & 0 \\
$\chi^{2}$ & & 0.225 & $/$ & $/$ & 4.356 \\
\hline$P$ & & 0.635 & 1.000 & 1.000 & 0.037 \\
\hline
\end{tabular}

\section{Note: * indicates analysis by Fisher's exact test}

\section{Discussion}

Acetabular fracture is a common and serious intra-articular fracture in clinical practice at present. It is preliminarily considered that patients suffering from high-energy injury are one of the important causes of acetabular fracture in clinical practice. In recent years, the incidence of this fracture type has been increasing year by year. This disease is mainly treated by reduction and internal fixation in clinical practice, while the fracture recovery effect after internal fixation mainly depends on the degree of fracture trauma, fracture reduction effect, quality of fracture internal fixation and prevention of postoperative complications ${ }^{[14]}$.

Traditional surgery for acetabular fracture can only roughly select the internal fixation according to the preoperative imaging data. In order to meet the shape of fracture reduction, the plate is repeatedly bent during the operation, which prolongs the operation time, increases the intraoperative blood loss and increases the risk of postoperative infection; This is followed by a decrease in the strength of the plate due to multiple pre-bending of the plate, which may lead to fatigue breakage of the plate after surgery, and the plate often fails to adhere well to the bone surface, reducing the fixation strength of the internal fixation and leading to the risk of displacement of the fracture. The length and direction of the screw cannot be accurately judged during surgery, resulting in a greatly increased risk of screw entry into the joint cavity, and repeated fluoroscopy during surgery also increases the radiation intake of the surgeon and patient. Traditional surgery is also difficult to achieve satisfactory reduction because of the deep location of the acetabulum and the limited surgical field during surgery, which increases the complications of postoperative traumatic arthritis.

3D printing technology can present acetabular fractures through 3D printing technology, and can also compare and observe the actual surgical operation and virtual model, so as to more intuitively and accurately understand the specific course of acetabular fractures, and clarify the fracture classification and fracture degree, especially for the observation of the articular surface of the posterior wall of the acetabulum and the internal damage of the joint, which can also be easily observed for those with articular surface compression, posterior column fractures and free bone fragments in the joint cavity, and then 
avoid missed diagnosis to a great extent. For patients with articular surface injury, 3D printing techniqueassisted surgery can also accurately determine the compression volume and rotation degree before surgery, further design individualized reduction plan, and guide the recovery of articular surface during surgery, while also avoiding the situation of excessive. After 3D printing technology assists the surgery to complete the preliminary reduction, the surgeon can observe the femoral head model, slightly adjust with reference to the unaffected hip joint to optimize the reduction, determine the successful reduction and then use the model to simulate the internal fixation implantation again, clarify the plate combination mode and length, and clarify the length of screws and the direction of screw insertion, which can not only effectively shorten the operation time, but also improve the surgical safety and avoid the occurrence of postoperative complications to a great extent ${ }^{[15]}$

There are many studies on the application of 3D printing technology in the surgical treatment of acetabular fracture, and the results are positive. However, there are few studies comparing and analyzing whether the application of 3D printing technology has a great effect on simple acetabular fracture or patients with complex acetabular fracture. In view of this, this study was conducted. The results showed that in patients with simple fracture, there was no statistical difference in the operation time, intraoperative blood loss, perioperative blood transfusion volume, intraoperative fluoroscopy times and postoperative drainage volume in the traditional surgical 3D printing technique-assisted surgery group $(P>0.05)$; And patients with simple acetabular fractures treated with 3D printing technology-assisted surgery and patients in the traditional surgery group were followed up for 3 months after surgery and found that there was no significant difference in their radiographic efficacy and hip function efficacy assessment; And there was no statistical difference in the incidence rate of postoperative complications between the two methods in patients with simple acetabular fractures, and this result indicated that there was no significant difference in the effect of 3D printing technology-assisted surgery for acetabular fractures compared with the traditional surgery group. In patients undergoing complex acetabular fracture surgery, the operation time of patients in 3D printing technology-assisted surgery group was significantly shorter than that in traditional surgery group, the intraoperative blood loss and perioperative blood transfusion volume were significantly less than those in traditional surgery group, and the number of intraoperative fluoroscopy was also significantly less than that in traditional surgery group, thereby reducing the radiation intake of surgical patients and surgical operators. The above results can preliminarily indicate that the application of 3D printing technology can develop individualized fracture reduction in advance and promote the smooth operation, so as to reduce the damage of surgical operation to soft tissue and peripheral neurovascular, which may also be the reason for the relatively low incidence rate of postoperative incision infection in the 3D printing technology-assisted surgery group. The results showed that the imaging efficacy at 3 months after operation in the 3D printing technique-assisted surgery group was significantly better than that in the traditional surgery group, and the overall response rate of the former was significantly higher than that of the latter (95.24\% vs $70.59 \%)$, and the difference had statistical significance. 3D printing technology is used in the surgical treatment of patients with complex acetabular fractures, which can effectively improve the postoperative hip function recovery of patients. White ${ }^{[16]}$ has also confirmed by research that the application of 3D printing technology promotes the effect of postoperative hip joint function recovery in patients undergoing complex acetabular fracture surgery. It is mainly considered that the fracture condition 
is observed by computer virtual surgery before acetabular fracture surgery, and the fracture reduction plan is made in order to accurately locate the free bone block, followed by smooth reduction, but also to avoid the impact of repeated fracture reduction and adjustment on the efficacy.

This study found that the incidence rate of complications such as iatrogenic neurological symptoms, traumatic arthritis, heterotopic ossification and incision infection in patients with simple acetabular fracture using 3D printing technology was not statistically different from that in the traditional surgery group $(P>0.05)$ (Table 8). However, the incidence rate of postoperative incision infection in patients with complex acetabular fracture treated with 3D printing technique-assisted surgery group was significantly lower than that in patients treated with traditional surgery group, which was consistent with the results of

${ }^{[17]}$ further confirming that the auxiliary application of 3D printing technology can effectively reduce the risk of postoperative infection of acetabular fracture. Heterotopic ossification is one of the common complications of acetabular fracture, and has a great impact on the recovery of hip joint function in patients after surgery. there was no statistical difference in the incidence of heterotopic ossification after different surgical treatments for patients with complex acetabular fractures in this study. It is mainly considered that there were few cases selected in this study. latrogenic nerve injury is also common after surgery, and it is currently mainly considered that surgeons do not know enough about the anatomical location of the posterior column of the posterior wall of the acetabulum and may overstretch the soft tissue during surgical procedures. Postoperative complications of acetabular fractures are inevitable, but most are avoidable, such as depending on the surgeon's experience.

In summary, acetabular fracture surgery is relatively technically demanding for the operating operator, so it is essential to make a correct fracture reduction plan preoperatively. 3D printing technology helps surgeons to understand the anatomy of the fracture site and its surrounding tissues by visually presenting the fracture site, which is more conducive to surgical operation and postoperative recovery; in addition, the application of this technology can select the appropriate internal fixation method and the required materials before surgery, and perform premolding, which can only be slightly adjusted during surgery, so it effectively shortens the operation time. Its effect is not obvious in patients undergoing simple acetabular fracture surgery, but it can effectively save the operation time, reduce intraoperative blood loss and perioperative blood transfusion volume in patients undergoing complex acetabular fracture surgery, while also reducing the number of intraoperative fluoroscopy and reducing the risk of postoperative complications, which shows that it has a high application value in patients undergoing complex acetabular fracture surgery. However, this study also has some defects, the number of cases included in the study is small, and the follow-up time is limited, so the value of 3D printing technology in reducing postoperative complications still needs to be further selected to prolong the follow-up time, and a prospective study is conducted.

\section{Conclusion}

The use of 3D printing technology in the adjuvant surgical treatment of patients with simple acetabular fractures has no significant effect on their operation time, intraoperative blood loss, perioperative blood 
transfusion volume, and intraoperative fluoroscopy times; 3D printing technology for adjuvant surgical treatment of patients with complex acetabular fractures can significantly shorten the operation time, reduce intraoperative blood loss and perioperative blood transfusion, and reduce the number of intraoperative fluoroscopy; 3D printing technology for auxiliary surgical treatment of complex acetabular fractures can effectively reduce the risk of postoperative incision infection

\section{Declarations}

\section{Ethics approval and consent to participate}

Ethical approval was granted by Ethics Committee of No. 971 Army Navy hospital of People's Liberation. Informed consent was obtained from all patients. All methods were carried out in accordance with relevant guidelines and regulations

\section{Consent for publication}

Not applicable

\section{Availability of data and materials}

The datasets used and/or analyzed during the current study are available from the corresponding author on reasonable request.

\section{Competing interests}

The authors declare that there are no potential conflicts of interest or competing interests with respect to the research, authorship, and/or publication of the work

\section{Funding}

The authors received no financial support for the research, authorship, and/ or publication of this article.

\section{Authors' contributions}

Xia Guo-feng and Liu Qi wrote the main manuscript text, took pictures, measured the data and calculated the data used SPSS. Sun Pei-feng reviewed and modified a part of inappropriate text.

\section{Acknowledgements}

The authors are grateful to Dr. Xia Yujun for providing 3D printing equipment.

\section{Authors' information}

Not applicable

\section{References}


1. Andersen RC, O'Toole RV, Nascone JW, Sciadini MF, Frisch HM, Turen CW. Modified stoppa approach for acetabular fractures with anterior and posterior column displacement: quantification of radiographic reduction and analysis of interobserver variability. J Orthop Trauma. 2010 May;24(5):271-8.

2. Andersen RC, O'Toole RV, Nascone JW, Sciadini MF, Frisch HM, Turen CW. Modified stoppa approach for acetabular fractures with anterior and posterior column displacement: quantification of radiographic reduction and analysis of interobserver variability. J Orthop Trauma. 2010 May;24(5):271-8.

3. Brouwers L., Pull ter Gunne A.F., de Jongh M.A.C., van der Heijden F.H.W.M., Leenen L.P.H., Spanjersberg W.R., van Helden S.H., Verbeek D.O., Bemelman M., Lansink K.W.W. The value of 3D printed models in understanding acetabular fractures. 3D Print. Addit. Manuf. 2018;5:37-46.

4. Awan O.A., Sheth M., Sullivan I., Hussain J., Jonnalagadda P., Ling S., Ali S. Efficacy of 3D Printed Models on Resident Learning and Understanding of Common Acetabular Fracturers. Acad. Radiol. 2019;26:130-135.

5. Manganaro M.S., Morag Y., Weadock W.J., Yablon C.M., Gaetke-Udager K., Stein E.B. Creating Threedimensional Printed Models of Acetabular Fractures for Use as Educational Tools. Radiogr. Rev. Publ. Radiol. Soc. N. Am. Inc. 2017;37:871-880.

6. Wang H., Lyu F., Sugand K., Wong S., Lin Y., Wang Q. Learning Acetabular Fracture Classification using a Three-Dimensional Interactive Software: A Randomized Controlled Trial. Anat. Sci. Educ. 2018;9:1-9.

7. Zheng Y.X., Yu D.F., Zhao J.G., Wu Y.L., Zheng B. 3D Printout Models vs. 3D-Rendered Images: Which Is Better for Preoperative Planning? J. Surg. Educ. 2016;73:518-523. doi: 10.1016/j.jsurg.2016.01.003. [PubMed] [CrossRef] [Google Scholar] [4] Capone A, Peri M, Mastio M. Surgical treatment of acetabular fractures in the elderly: a systematic review of the results:[J]. Efort Open Reviews, 2017, 2(4):97-103.

8. Tack P., Victor J., Gemmel P., Annemans L. 3D-printing techniques in a medical setting: A systematic literature review. Biomed. Eng. Online. 2016;15:1-22.

9. Capone A, Peri M, Mastio M. Surgical treatment of acetabular fractures in the elderly: a systematic review of the results:[J]. Efort Open Reviews, 2017, 2(4):97-103.

10. Lal SR. Outcome of surgical treatment for displaced acetabular fractures: a prospective study. Rev Bras Ortop. 2017 Dec 29;53(4):482-488.

11. Verbeek DO, van der List JP, Tissue CM, Helfet DL. Long-term patient reported outcomes following acetabular fracture fixation. Injury. 2018 Jun;49(6):1131-1136.

12. Matta JM, Tornetta $P$ 3rd.Internal fixation of unstable pelvicring injures[J].Clinic Orthop Res, 1996(329): 129-140.

13. Aubign6 RM, Postel M.Functional results of hip Arthroplasty With acrylic prosthesis[J].J Bone Joint Surg(Am), 1954, 36(3): 451-475.

14. Borg T, Hailer N P. Outcome 5 years after surgical treatment of acetabular fractures: a prospective clinical and radiographic follow-up of 101 patients[J]. Archives of Orthopaedic \& Trauma Surgery, 2015, 135(2):227. 
15. Dailey SK, Phillips CT, Radley JM, Archdeacon MT. Achieving Anatomic Acetabular Fracture ReductionWhen is the Best Time to Operate? J Orthop Trauma. 2016 Aug;30(8):426-31.

16. White G, Kanakaris NK, Faour O, Valverde JA, Martin MA, Giannoudis PV. quadrilateral plate fractures of the acetabulum: an update[J].Injury,2013,44(2):159 167.

17. Maini L, Batra S, Arora S, Singh S, Kumar S, Gautam VK. Surgical dislocation of the hip for reduction of acetabular fracture and evaluation of chondral damage[J].J Orthop Surg (Hong Kong),2014,22(1):18 23.

\section{Figures}

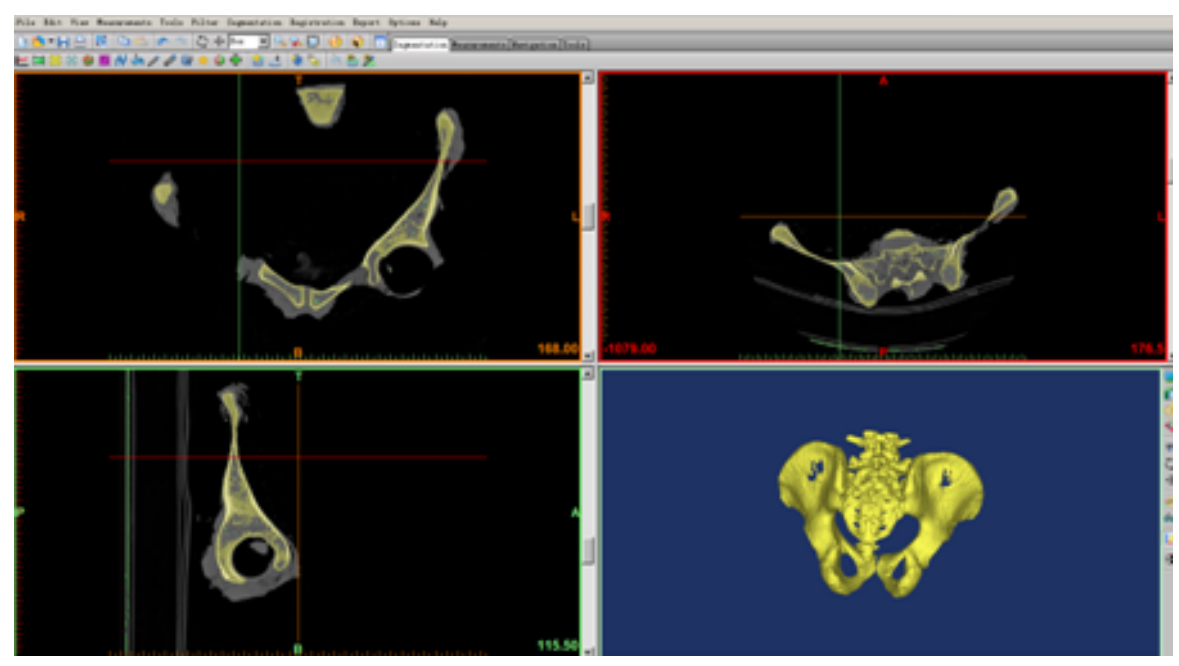

\section{Figure 1}

Import Dicom file, determine model threshold, reconstruct bone
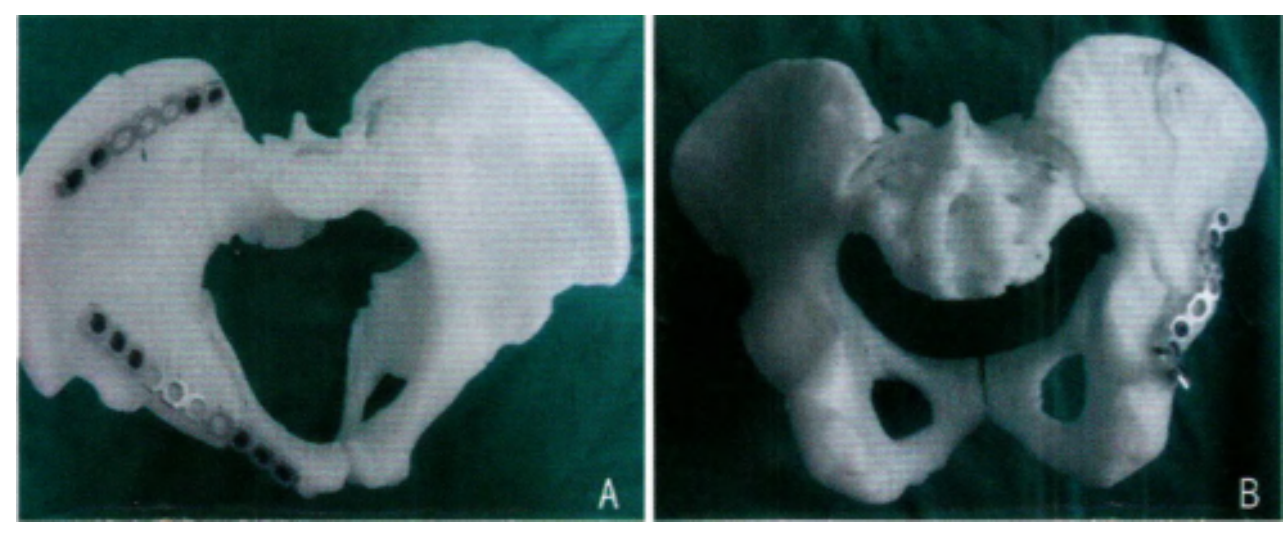

Figure 2

Printing acetabular fracture reduction model by 3D printing technology 

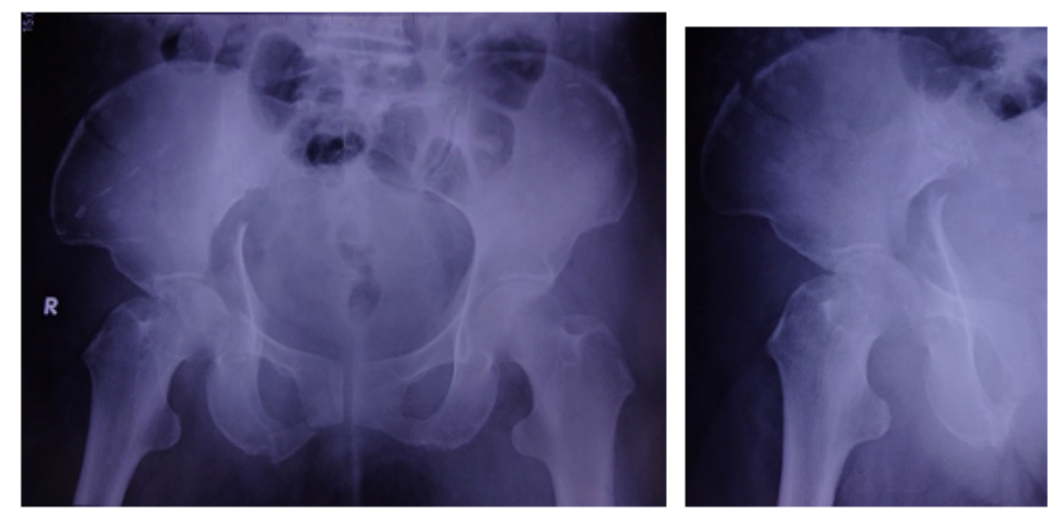

a

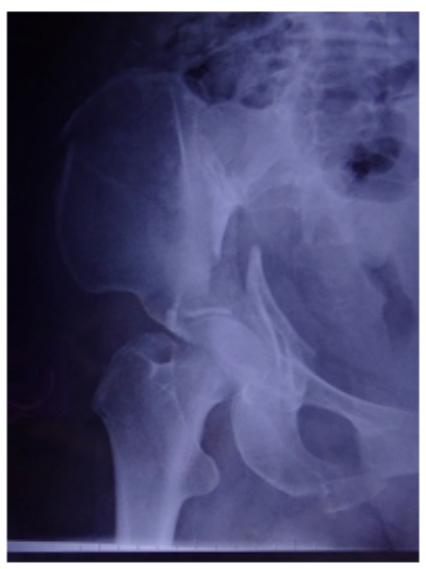

b

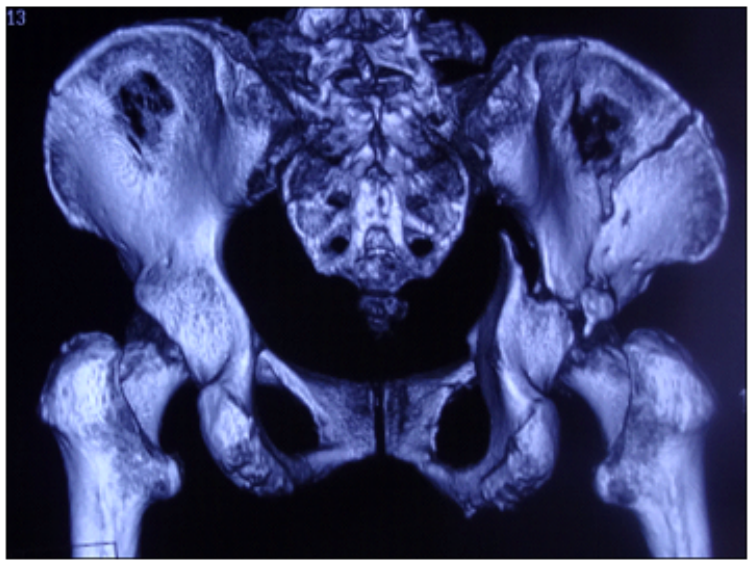

$\mathrm{c}$

d

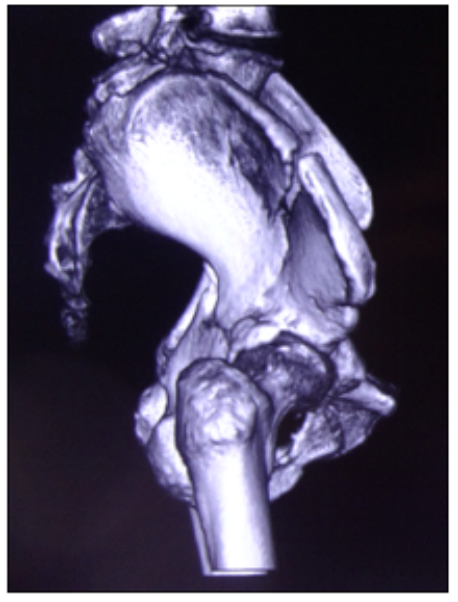

$\mathrm{e}$

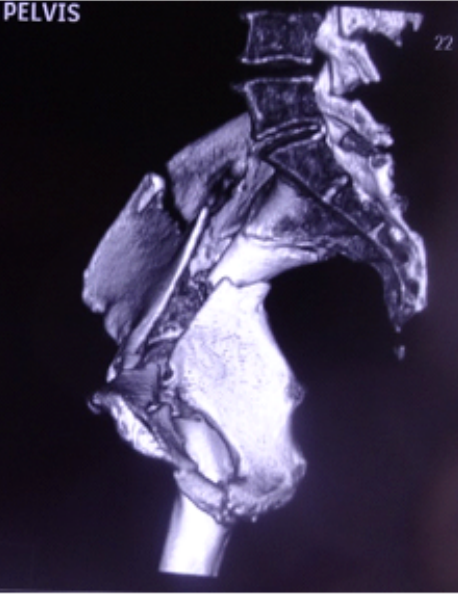

f

\section{Figure 3}

$\mathrm{A}$ is preoperative pelvic anteroposterior $\mathrm{X}$-ray, $\mathrm{b}$ is preoperative pelvic iliac oblique $\mathrm{X}$-ray, $\mathrm{c}$ is preoperative pelvic closed hole oblique $\mathrm{X}$-ray, $\mathrm{d}$-f is preoperative pelvic three-dimensional reconstruction

CT image 


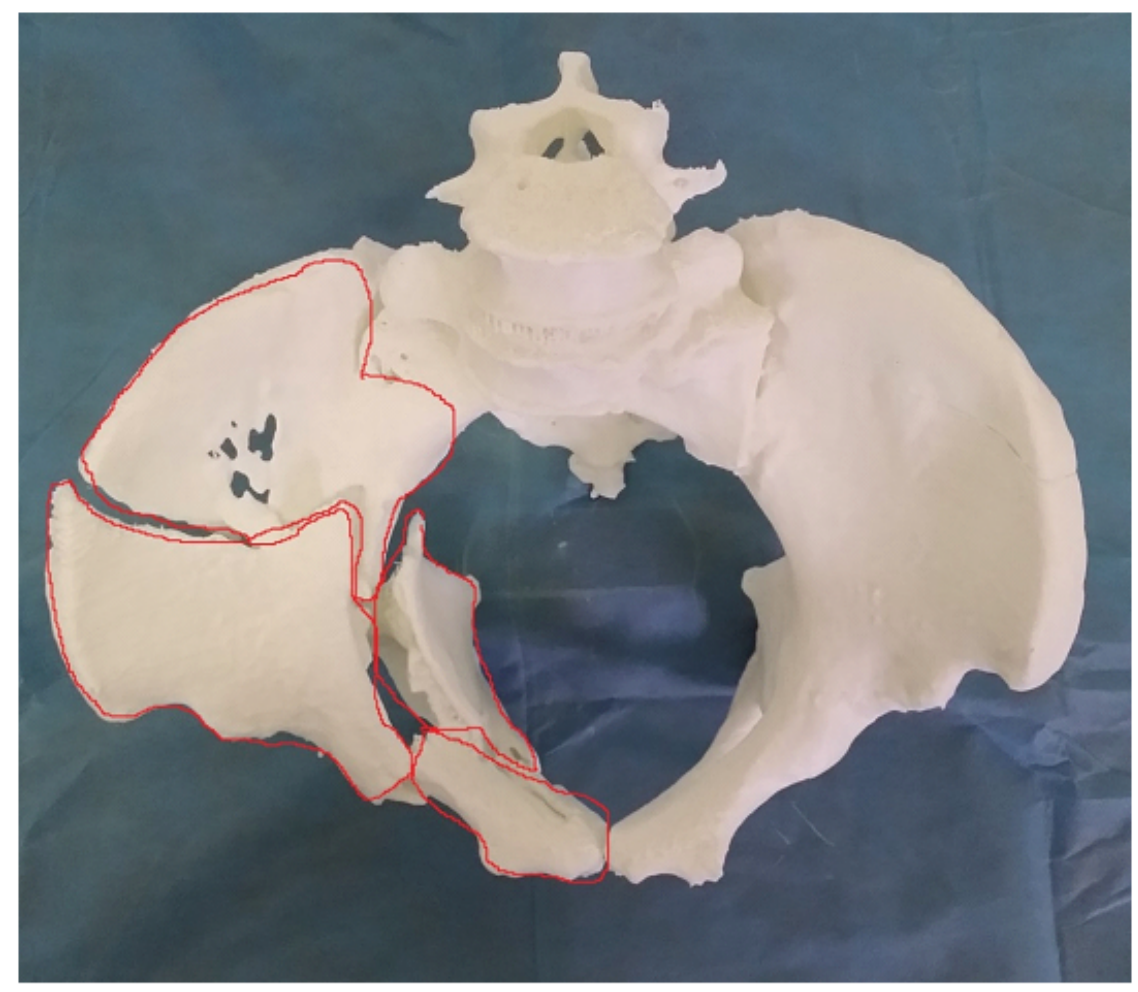

a

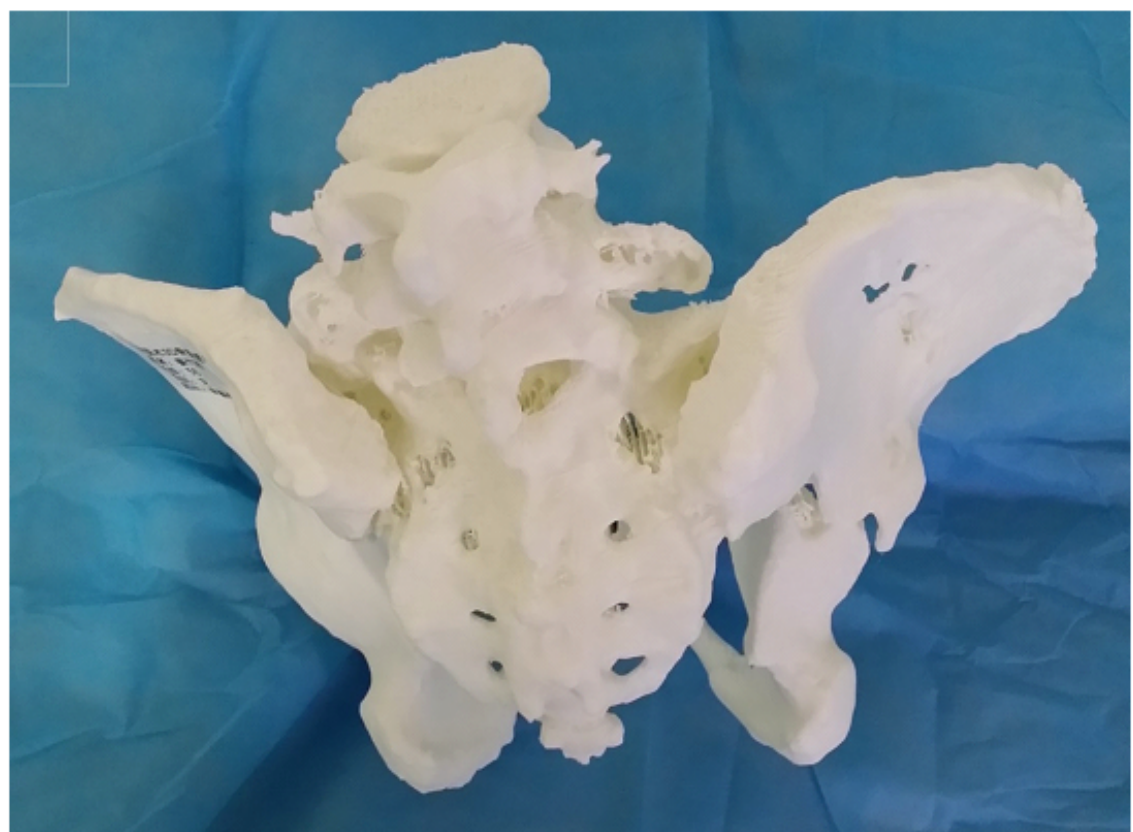

$\mathrm{b}$

\section{Figure 4}

a-b is a preoperative 3D printed model, showing right anterior acetabular column + posterior hemitransverse acetabular fracture 


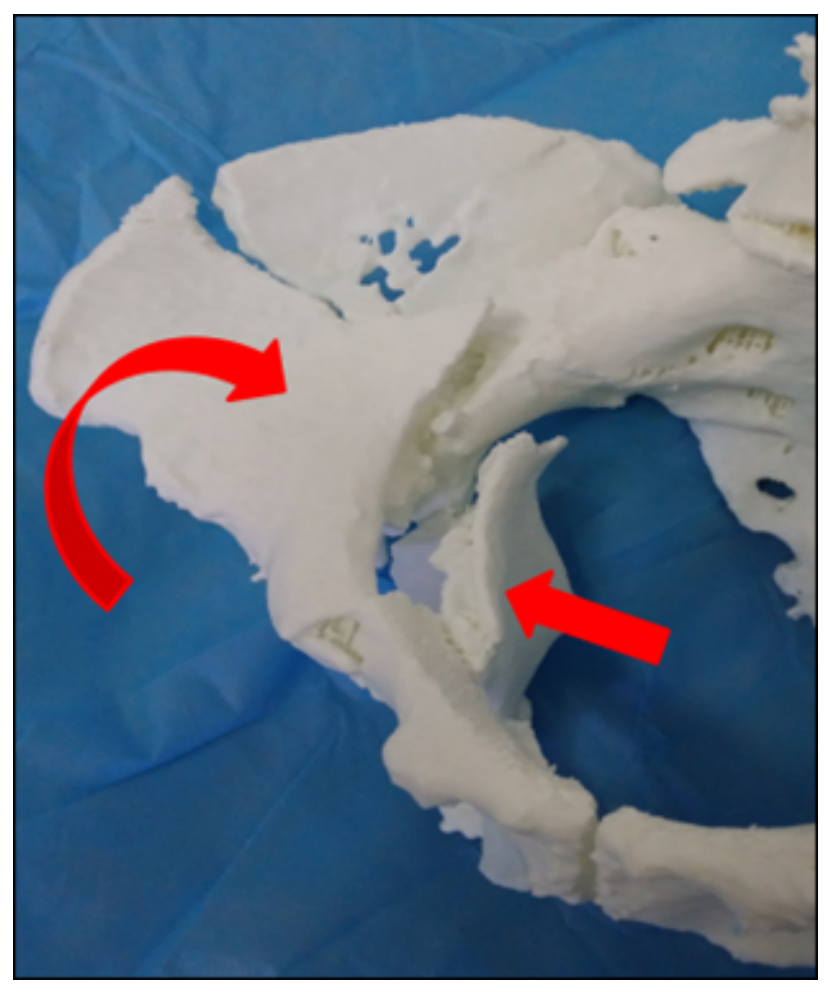

Figure 5

Preoperative surgical design 


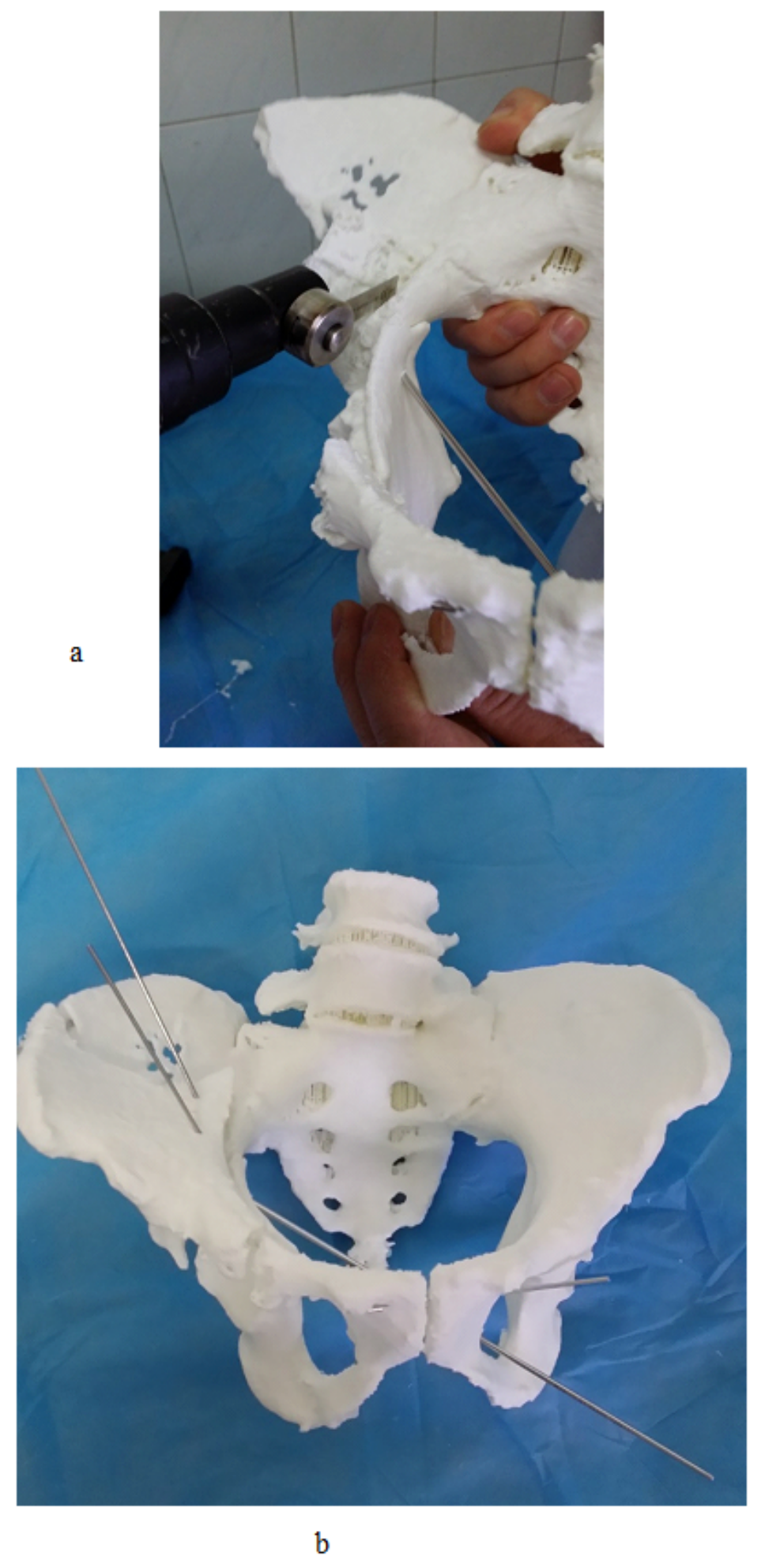

Figure 6

a-b Shows preoperative surgical virtual reduction, temporary fixation 


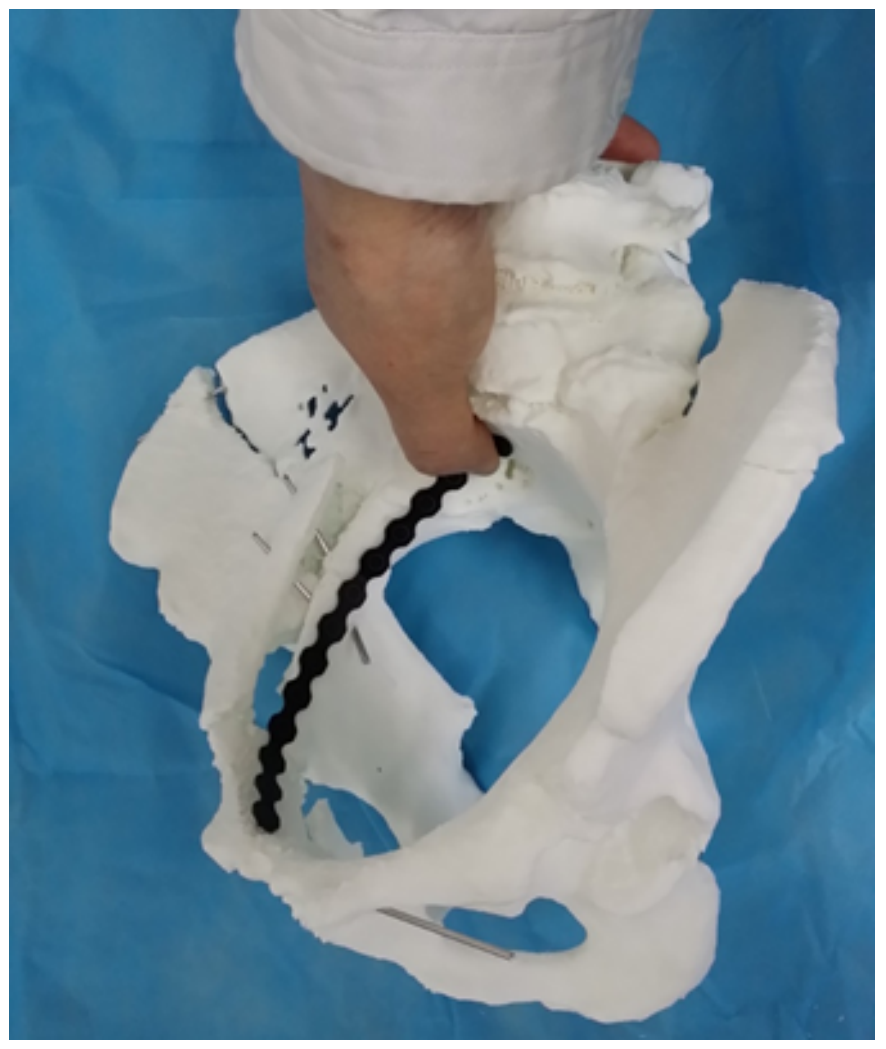

Figure 7

Design effective fixation range of bone plate

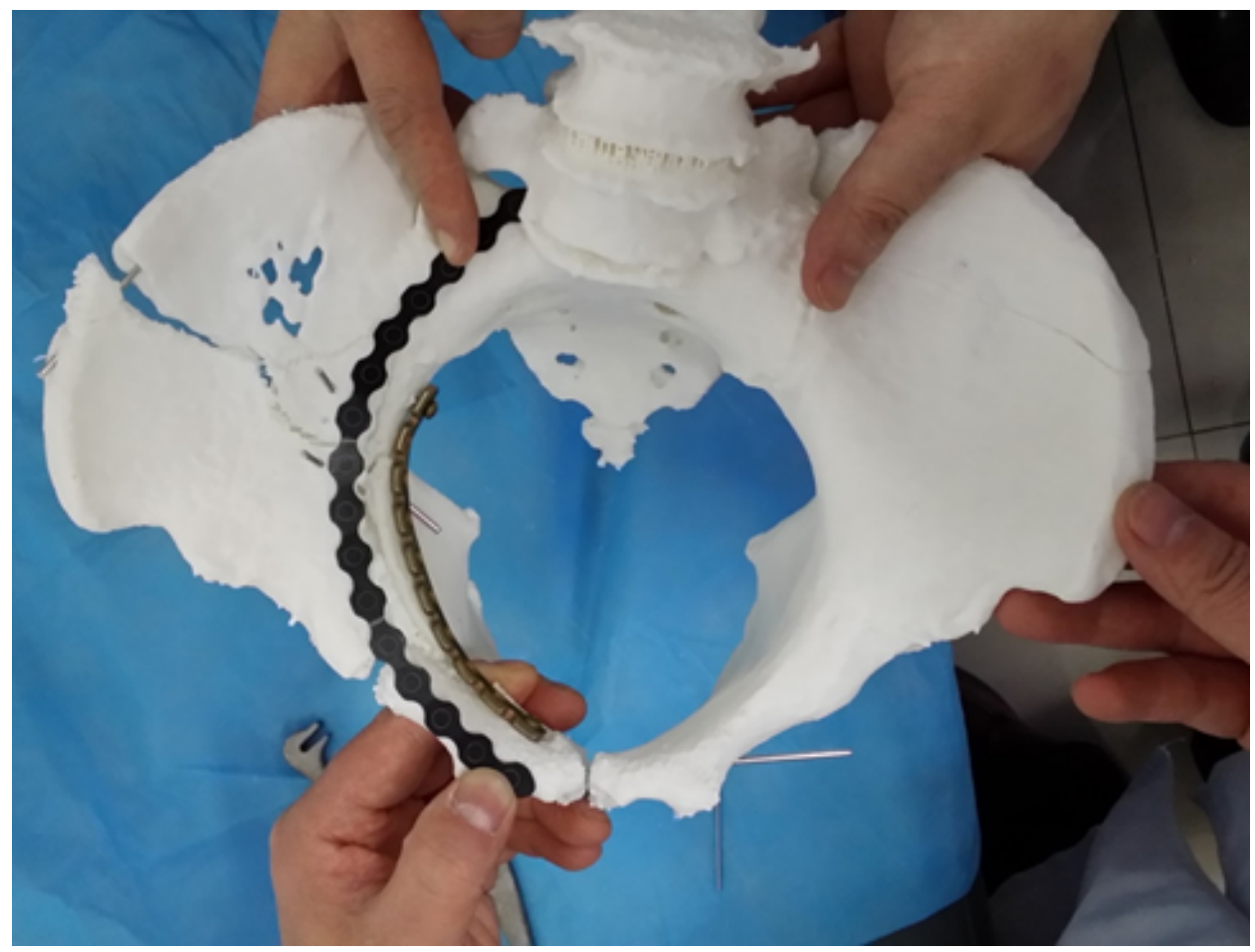

Figure 8 
Pre-bent bone plate, design screw position

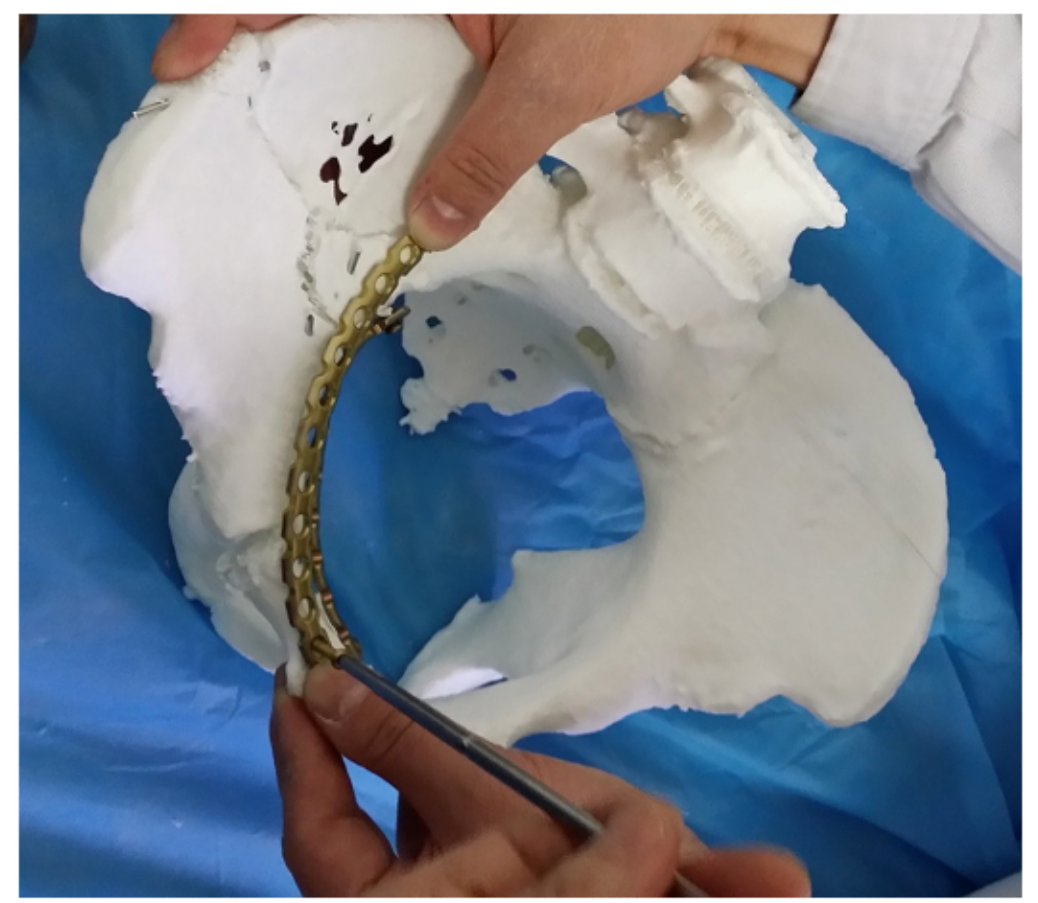

a

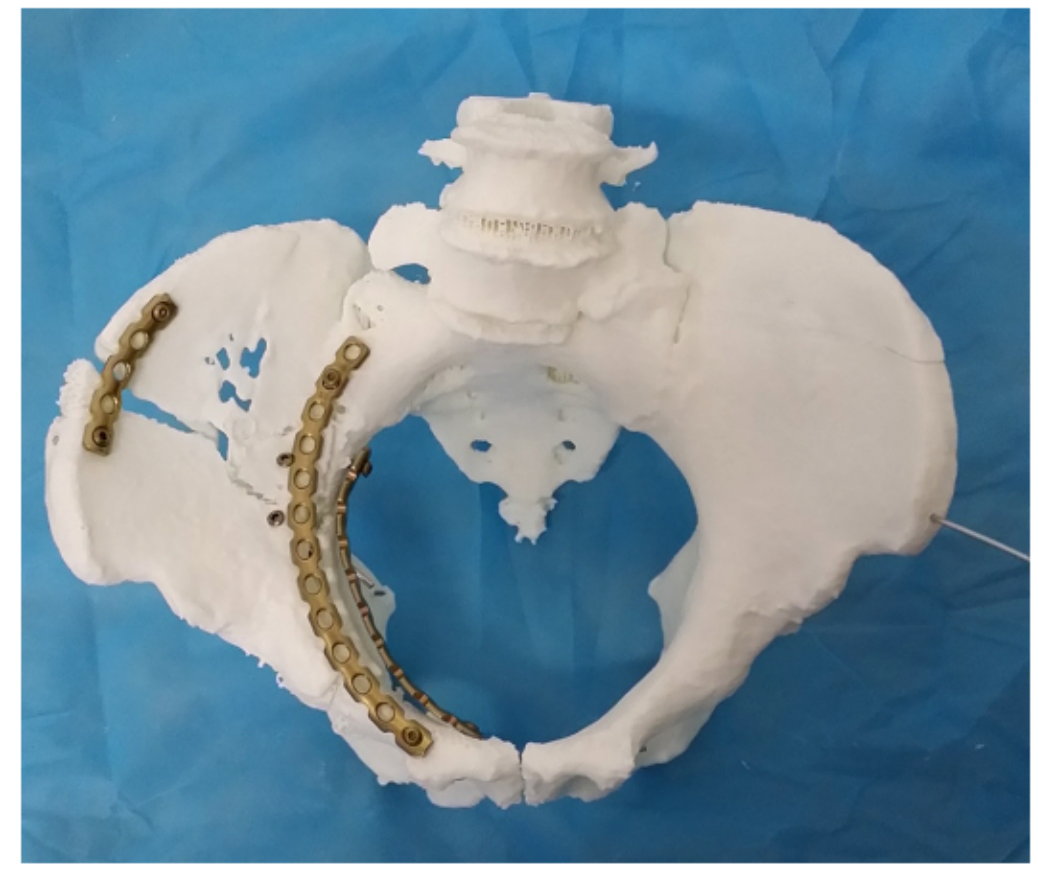

b

Figure 9

$a-b$ represents surgery demonstration 

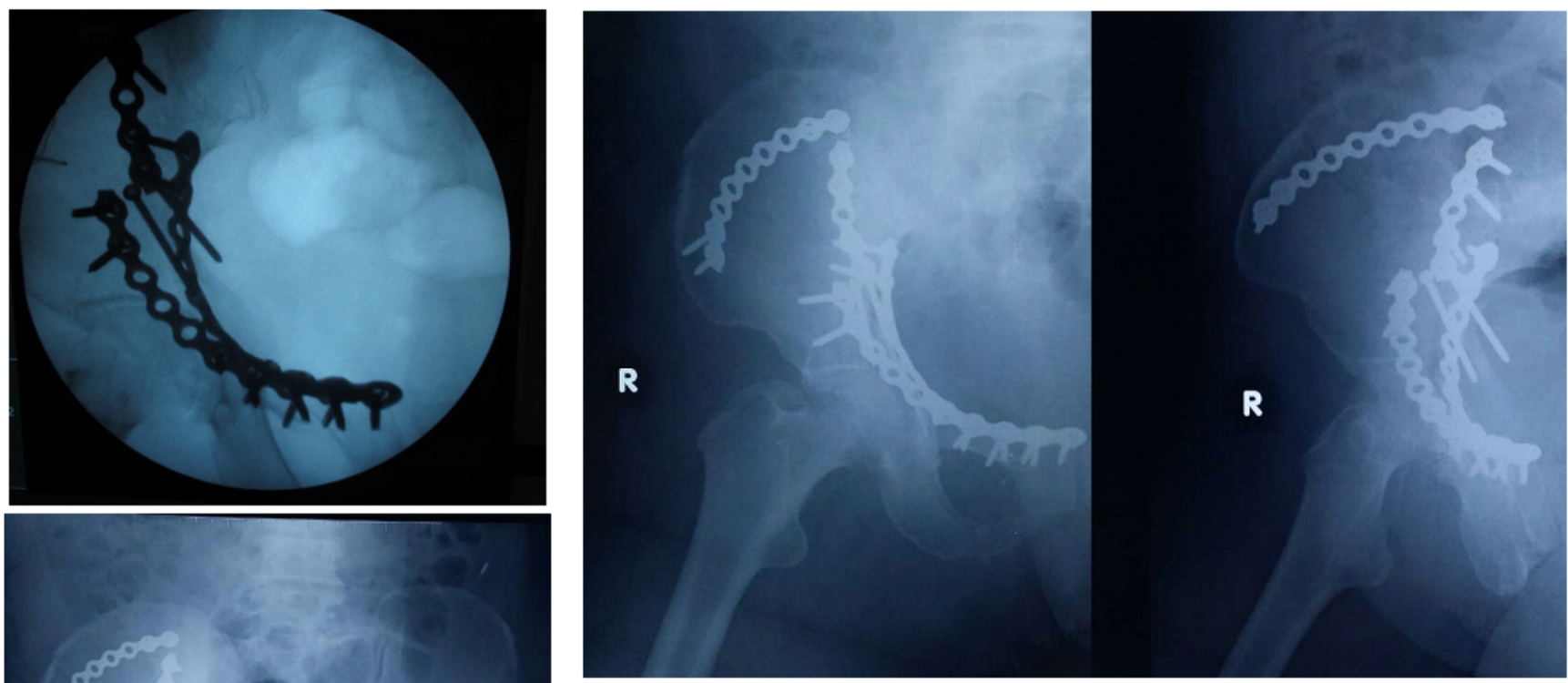

b

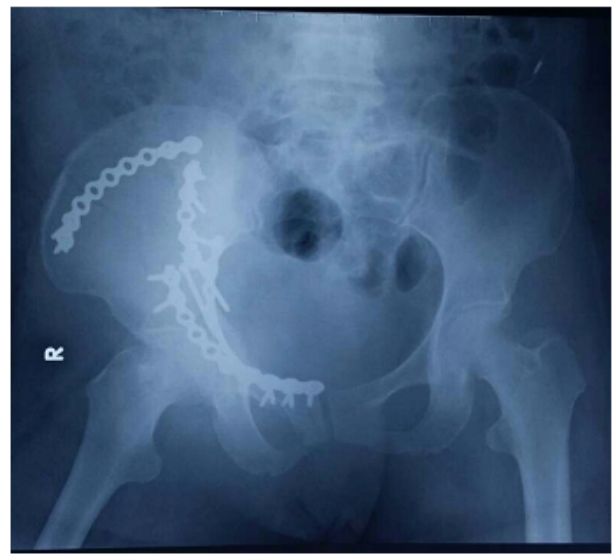

c

Figure 10

a For intraoperative fluoroscopy reference, $\mathrm{b}$ for postoperative pelvic anteroposterior X-ray, $\mathrm{c}$ for postoperative pelvic closed hole oblique, iliac oblique X-ray, indicating that the right acetabular anterior, posterior column, iliac wing fractures have been reduced, and the plate position is good 